\title{
Load-Resistance- and Voltage-Tunable Photovoltaic Effect in Tilting Manganite Films
}

\author{
X. L. Han, ${ }^{1,2}$ H. Ni, ${ }^{2}$ K. Zhao, ${ }^{1,2,3,4}$ Y.-C. Kong, ${ }^{3}$ H. K. Wong, ${ }^{3}$ and S. Q. Zhao ${ }^{2}$ \\ ${ }^{1}$ State Key Laboratory of Heavy Oil Processing, China University of Petroleum, Beijing 102249, China \\ ${ }^{2}$ College of Science, China University of Petroleum, Beijing 102249, China \\ ${ }^{3}$ Department of Physics, The Chinese University of Hong Kong, Hong Kong \\ ${ }^{4}$ International Center for Materials Physics, Chinese Academy of Sciences, Shenyang 110016, China \\ Correspondence should be addressed to K.Zhao, zhk@cup.edu.cn
}

Received 24 April 2011; Accepted 30 August 2011

Academic Editor: Vincenzo Augugliaro

Copyright (๑) 2011 X. L. Han et al. This is an open access article distributed under the Creative Commons Attribution License, which permits unrestricted use, distribution, and reproduction in any medium, provided the original work is properly cited.

The photovoltaic properties of miscut $\mathrm{La}_{2 / 3} \mathrm{Ca}_{1 / 3} \mathrm{MnO}_{3}$ films were systematically investigated with different bias voltage $\left(V_{b}\right)$ and load resistance $\left(R_{S}\right)$. The photoresponse depended strongly on $V_{b}$ and $R_{S}$ and was improved greatly by increasing $V_{b}$ and $R_{S}$. The maximum photovolvaic sensitivity reached $62.5 \mathrm{mV} / \mathrm{mJ}$. The present results suggested the promising potential of increasing $V_{b}$ and $R_{S}$ in high-sensitivity detectors.

\section{Introduction}

Hydrocarbon resource is important and strategic for the national modernization, defense, and security. Present concept of Digital Oilfield suggests that an optical detector in oil well can operate at high temperature upto $\sim 500^{\circ} \mathrm{C}$ and high pressure upto $\sim 100 \mathrm{MPa}$ with high-speed response. Recently there have been active studies of the photoresponse characteristics in the manganite thin films which can work in a harsh environment (features such as thermal instability and high pressure). Technological interest has centered on bolometers [1], while more basic issues have involved quasiparticle generation and carrier relation times [2-6]. Ultrafast photovoltaic effect has been observed in manganite oxide with a picosecond response time, which was due to a combination mechanism of photoinduced carriers and Seebeck effect [7-9].

In this work, to improve the photosensitivity of manganite films and meet the needs of oil and gas optical engineering, we focused on load-resistance- $\left(R_{S^{-}}\right)$and bias-voltage$\left(V_{b^{-}}\right)$tunable lateral photovoltages of $\mathrm{La}_{2 / 3} \mathrm{Ca}_{1 / 3} \mathrm{MnO}_{3}$ (LCMO) films grown on miscut $\mathrm{LaSrAlO}_{4}$ (LSAO) substrates with $10^{\circ}$ tilted to [001] direction of LSAO. The laser-induced voltage (LIV) depended strongly on $V_{b}$ and $R_{S}$. Under an irradiation of $248 \mathrm{~nm}$ ultraviolet laser, when $V_{b}$ is changed from 30 to $-30 \mathrm{~V}$, the LIV peak sensitivity can be tuned from -10.8 to $12.5 \mathrm{mV} / \mathrm{mJ}$ and from -52.1 to $62.5 \mathrm{mV} / \mathrm{mJ}$ at $R_{S}=10$ and $72 \Omega$, respectively.

\section{Experimental}

A LCMO $(120 \mathrm{~nm})$ thin film was deposited by facing-target sputtering technique on the LSAO substrate cut along the (001) surface with an intentional $10^{\circ}$ vicinal angle toward the $[010]$ direction $[10,11]$. The substrate temperature was kept at $680^{\circ} \mathrm{C}$ with the oxygen pressure of 30 mTorr during deposition. After the deposition, the vacuum chamber was immediately backfilled with $1 \mathrm{~atm}$ oxygen. The LCMO film was then cooled to room temperature with the substrate heater power cutoff.

Figure 1 shows the schematic circuit of the photoresponse measurement. Before the measurement, the sample was carefully cleaned using alcohol and acetone. Two colloidal silver electrodes of $1 \mathrm{~mm} \times 2.5 \mathrm{~mm}$ area were prepared on LCMO surface. Compex 50 excimer-pulsed laser was used as the light source, operating at a wavelength of $248 \mathrm{~nm}$ with $20 \mathrm{~ns}$ duration at a repetition rate of $1 \mathrm{~Hz}$. The on-sample 


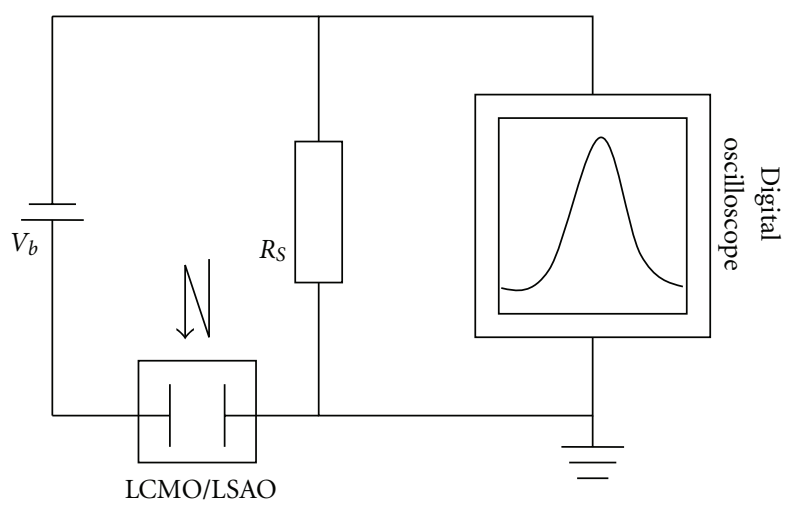

FIgURE 1: The schematic circuit of the sample measurement.

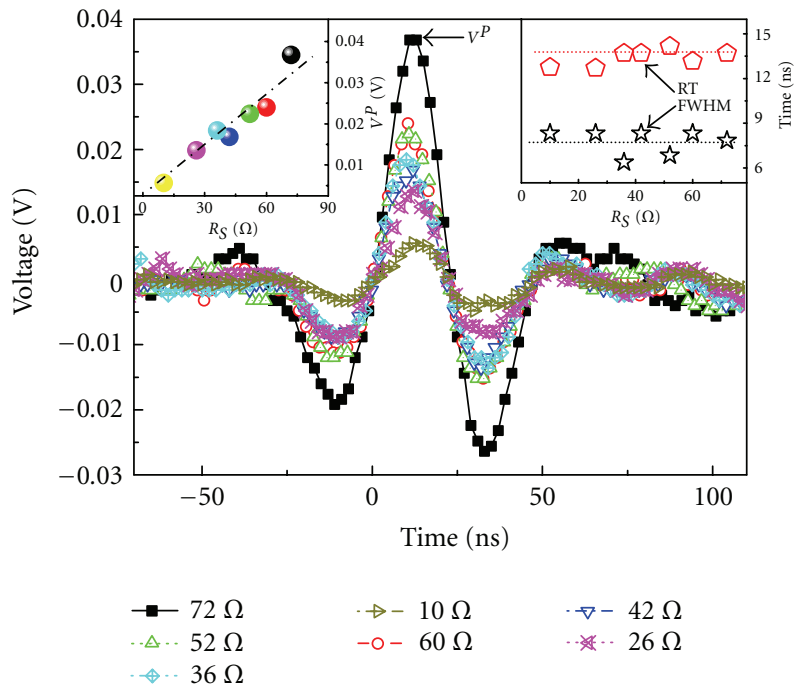

FIgURE 2: Waveforms for different load resistance $R_{S}$ at $V_{b}=0 \mathrm{~V}$ under the $248 \mathrm{~nm}$ laser illumination. The left inset shows the dependence of $V^{P}$ on $R_{S}$. The right inset displays the RT and FWHM as functions of $R_{S}$.

laser pulse energy is $2.88 \mathrm{~mJ}$. The waveforms were recorded by a sampling oscilloscope with an input impedance of $1 \mathrm{M} \Omega$. All the measurements were carried out at room temperature.

\section{Results and Discussion}

Figure 2 shows a typical voltage transient of LCMO film under the $248 \mathrm{~nm}$ laser irradiation without bias $\left(V_{b}=\right.$ $0 \mathrm{~V})$. The rise time (RT) and full width at half-maximum (FWHM) are independent of $R_{S}$ and $7 \mathrm{~ns}$ and $13 \mathrm{~ns}$, respectively. As reviewed in the left inset of Figure 2, the peak voltage signal $V^{P}$ has a linear relationship with the $R_{S}$ from 10 to $72 \Omega$.

The laser-induced voltage waveform is plotted in Figures $3(\mathrm{a})$ and $3(\mathrm{~b})$ as a function of time, and the photovoltage peak value $V^{P}$ increases monotonously from -0.15 to $0.18 \mathrm{~V}$ and from -0.031 to $0.036 \mathrm{~V}$ with $V_{b}$ from 30 to $-30 \mathrm{~V}$ at $R_{S}=72$ and $10 \Omega$. Figure 3(c) reviews $V^{P}$ as a function of applied bias voltage $V_{b}$, which depended linearly on $V_{b}$ and showed no saturation for selected $R_{S}$. In addition, $V^{P}$ is also very sensitive to the load resistance $R_{S}$ and shows a higher value for a larger $R_{S}$. As shown in Figure 3(d), the10-90\% rise time RT of the photovoltaic signals nearly keeps constant with varying $R_{S}$, while the response speed is faster for the lower bias and the RT difference between $V_{b}=0$ and $30 \mathrm{~V}$ is about $10 \mathrm{~ns}$.

Figure 4 summarizes the spatial distribution of the $V^{P}$ as a function of $R_{S}$ and $V_{b} .\left|V^{P}\right|$ shows a higher value for a larger $V_{b}$ while a lower value for a smaller $V_{b}$ and increases with increasing load resistance $R_{S}$. The result indicates the potential possibility to improve the photovoltage sensitivity by introducing the load resistance and applying bias voltage.

Since the photon energy of $248 \mathrm{~nm}$ wavelength $(4.86 \mathrm{eV})$ is above the bandgap of LCMO $(\sim 1.2 \mathrm{eV})$, electron-hole pairs 


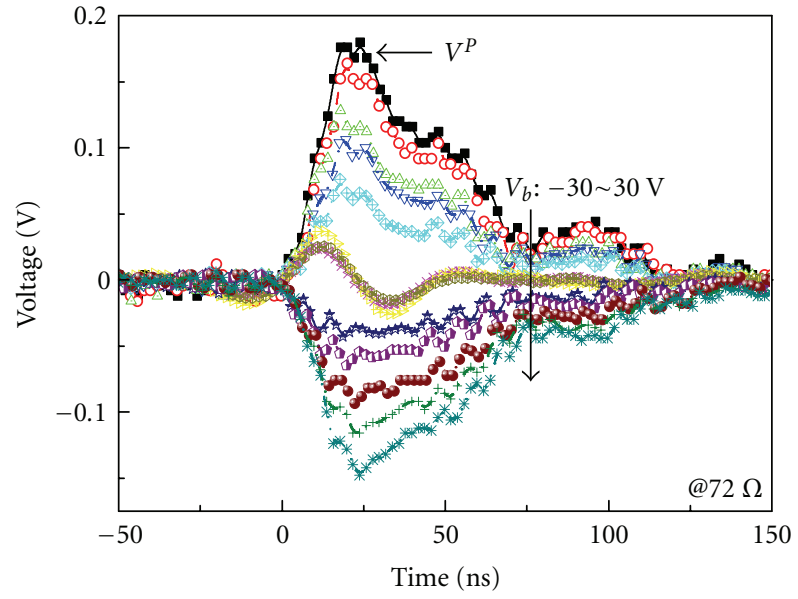

(a)

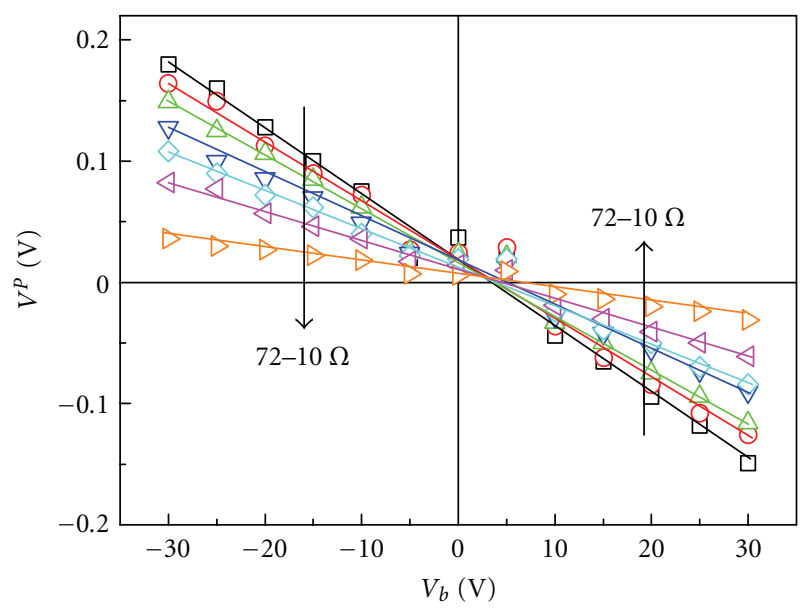

(c)

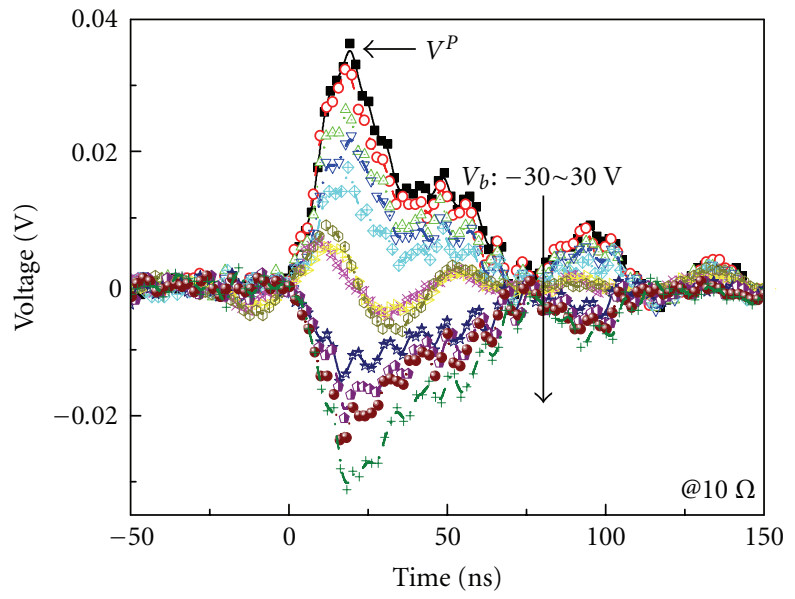

(b)

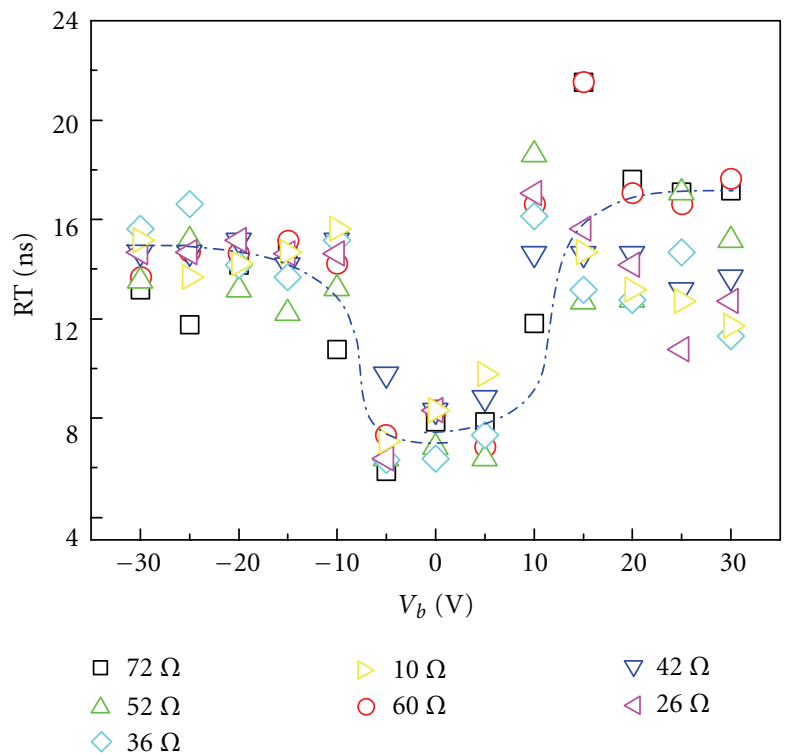

(d)

FIGURE 3: Photovoltage as a function of time with (a) $R_{S}=72 \Omega$ and (b) $R_{S}=10 \Omega$ under $248 \mathrm{~nm}$ laser pulses at different bias voltage $V_{b}$. (c) $V^{P}$ and (d) rise time RT as a function of $V_{b}$.

are generated in the LCMO film. In our case, the laser we used is a $248 \mathrm{~nm} \mathrm{KrF}$ excite laser beam in duration of $20 \mathrm{~ns}$, so the amount of laser-induced carriers should be comparable with or even much larger than that of the majority carriers in the LCMO; on the other hand, there exists no built-in field which exists in the $\mathrm{p}$-n junction to separate holes and electrons. Therefore, both the electrons and holes play an important role in the photovoltaic. Under the external bias, the carriers are sped up and the photoresponse is enhanced.

From the basic laws of circuit networks, the readout voltage $V_{S}$ from the oscilloscope can be calculated from $V_{S}=$ $\left(V_{b}-V_{0}\right) R_{S} /\left(R_{S}+R_{0}\right)$, where $V_{0}$ is the voltage signal generated in the sample and $R_{0}$ is the sample impedance. In our case, the load resistance is small and $R_{S} \ll R_{0}$. Thus, $V_{S}$ can be presented as $V_{S} \approx\left(V_{b}-V_{0}\right) R_{S} / R_{0} \propto R_{S}$ as shown in Figures 2 and 4.

\section{Conclusions}

In summary, the bias and load resistance-dependent photovoltaic effects in LCMO thin film grown on miscut LSAO were studied systematically. With the increase in $V_{b}$ and $R_{S}$, the peak photovoltage signals increase monotonically and a maximum of $0.18 \mathrm{~V}$ was achieved at $R_{S}=72 \Omega, V_{b}=30 \mathrm{~V}$. The experimental results showed that increasing $V_{b}$ and $R_{S}$ is an effective method for improving the photovoltage sensitivity in manganite, suggesting the potential for optoelectronic detection applications. 


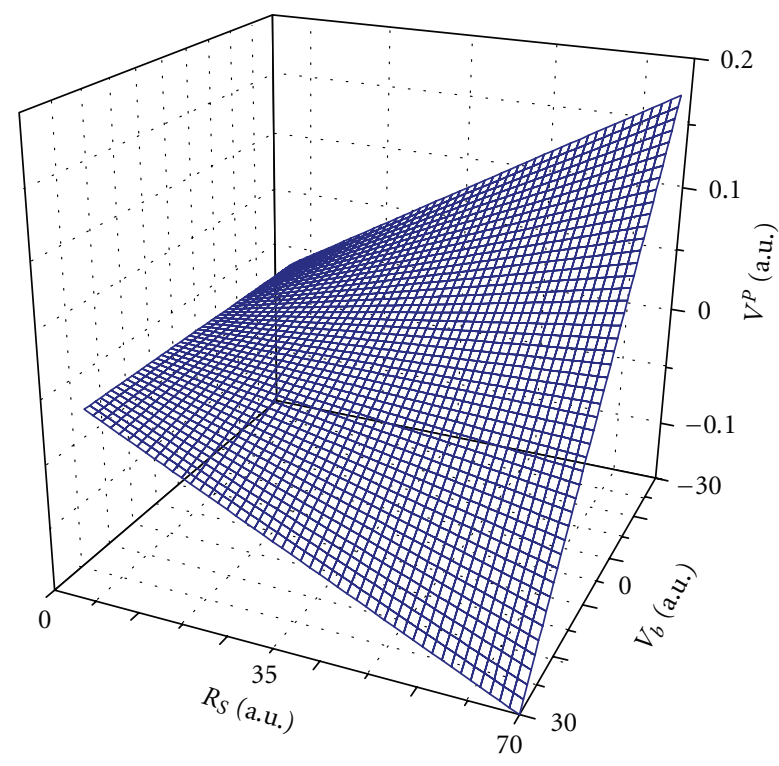

Figure 4: Three-dimensional plot for $V^{P}$ as a function of $R_{S}$ and $V_{b}$. grown on vicinal $\mathrm{SrTiO}_{3}$ (001) substrates," Journal of Physics D, vol. 40, no. 18, pp. 5703-5706, 2007.

[9] K. Zhao, Y. H. Huang, H. B. Lu et al., "Anomalous photovoltaic effect in $\mathrm{La}_{0.8} \mathrm{Sr}_{0.2} \mathrm{MnO}_{3}$ films grown on $\mathrm{SrTiO}_{3}$ (001) substrates by laser molecular beam epitaxy," EPJ Applied Physics, vol. 35, no. 3, pp. 173-176, 2006.

[10] X. T. Zeng and H. K. Wong, "Epitaxial growth of single-crystal (La,Ca) $\mathrm{MnO}_{3}$ thin films," Applied Physics Letters, vol. 66, no. 24, pp. 3371-3373, 1995.

[11] Z. J. Yue, K. Zhao, H. Ni et al., "Photo-induced magnetoresistance enhancement in manganite heterojunction at room temperature," Journal of Physics D, vol. 44, Article ID 095103, 2011.

\section{Acknowledgments}

This work has been supported by NCET, NSFC, RFDP, and Direct Grant from the Research Grants Council of the Hong Kong Special Administrative Region (Grant no. C0012060295).

\section{References}

[1] M. Rajeswari, C. H. Chen, A. Goyal et al., "Low-frequency optical response in epitaxial thin films of $\mathrm{La}_{0.67} \mathrm{Ca}_{0.33} \mathrm{MnO}_{3}$ exhibiting colossal magnetoresistance," Applied Physics Letters, vol. 68, no. 25, pp. 3555-3557, 1996.

[2] Y. G. Zhao, J. J. Li, R. Shreekala et al., "Ultrafast laser induced conductive and resistive transients in $\mathrm{La}_{0.7} \mathrm{Ca}_{0.3} \mathrm{MnO}_{3}$ : charge transfer and relaxation dynamics," Physical Review Letters, vol. 81, no. 6, pp. 1310-1313, 1998.

[3] R. D. Averitt, A. I. Lobad, C. Kwon, S. A. Trugman, V. K. Thorsmølle, and A. J. Taylor, "Ultrafast conductivity dynamics in colossal magnetoresistance manganites," Physical Review Letters, vol. 87, no. 1, Article ID 017401, pp. 1-4, 2001.

[4] K. Zhao, K. J. Jin, H. Lu et al., "Transient lateral photovoltaic effect in p-n heterojunctions of $\mathrm{La}_{0.7} \mathrm{Sr}_{0.3} \mathrm{MnO}_{3}$ and $\mathrm{Si}$," Applied Physics Letters, vol. 88, no. 14, Article ID 141914, 2006.

[5] K. Zhao, K. J. Jin, H. B. Lu et al., "Electrical-modulated magnetoresistance in multi- $\mathrm{p}-\mathrm{n}$ heterojunctions of $\mathrm{La}_{0.9} \mathrm{Sr}_{0.1} \mathrm{MnO}_{3}$ and oxygen-vacant $\mathrm{SrTi}_{3-\delta}$ on Si substrates," Applied Physics Letters, vol. 93, no. 25, Article ID 252110, 2008.

[6] H. Liu, K. Zhao, N. Zhou et al., "Photovoltaic effect in micrometer-thick perovskite-type oxide multilayers on Si substrates," Applied Physics Letters, vol. 93, no. 17, Article ID 171911, 2008.

[7] K. Zhao, K. J. Jin, Y. H. Huang et al., "Laser-induced ultrafast photovoltaic effect in $\mathrm{La}_{0.67} \mathrm{Ca}_{0.33} \mathrm{MnO}_{3}$ films at room temperature," Physica B, vol. 373, no. 1, pp. 72-75, 2006.

[8] K. Zhao, M. He, G. Z. Liu, and H. B. Lu, "Photo-induced voltage characteristics of $\mathrm{La}_{0.9} \mathrm{Sr}_{0.1} \mathrm{MnO}_{3}$ films epitaxially 


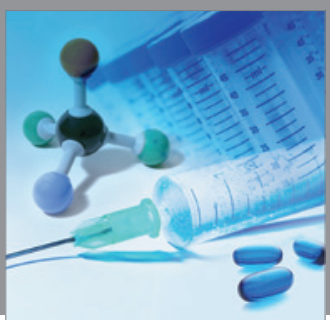

International Journal of

Medicinal Chemistry

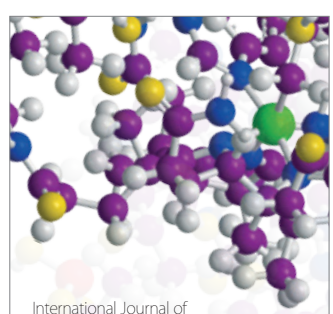

Carbohydrate Chemistry

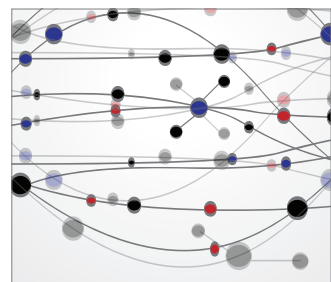

The Scientific World Journal
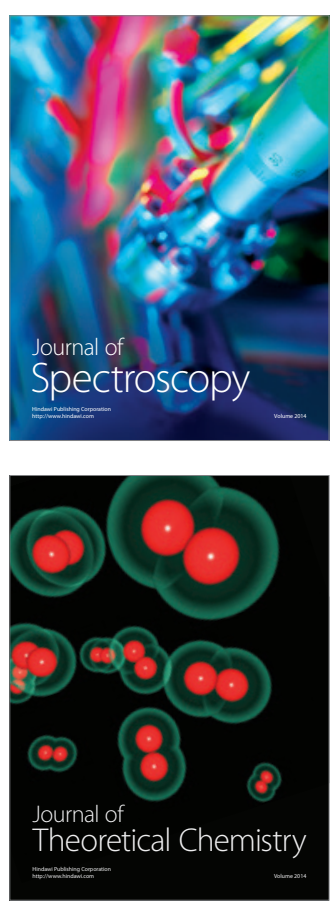
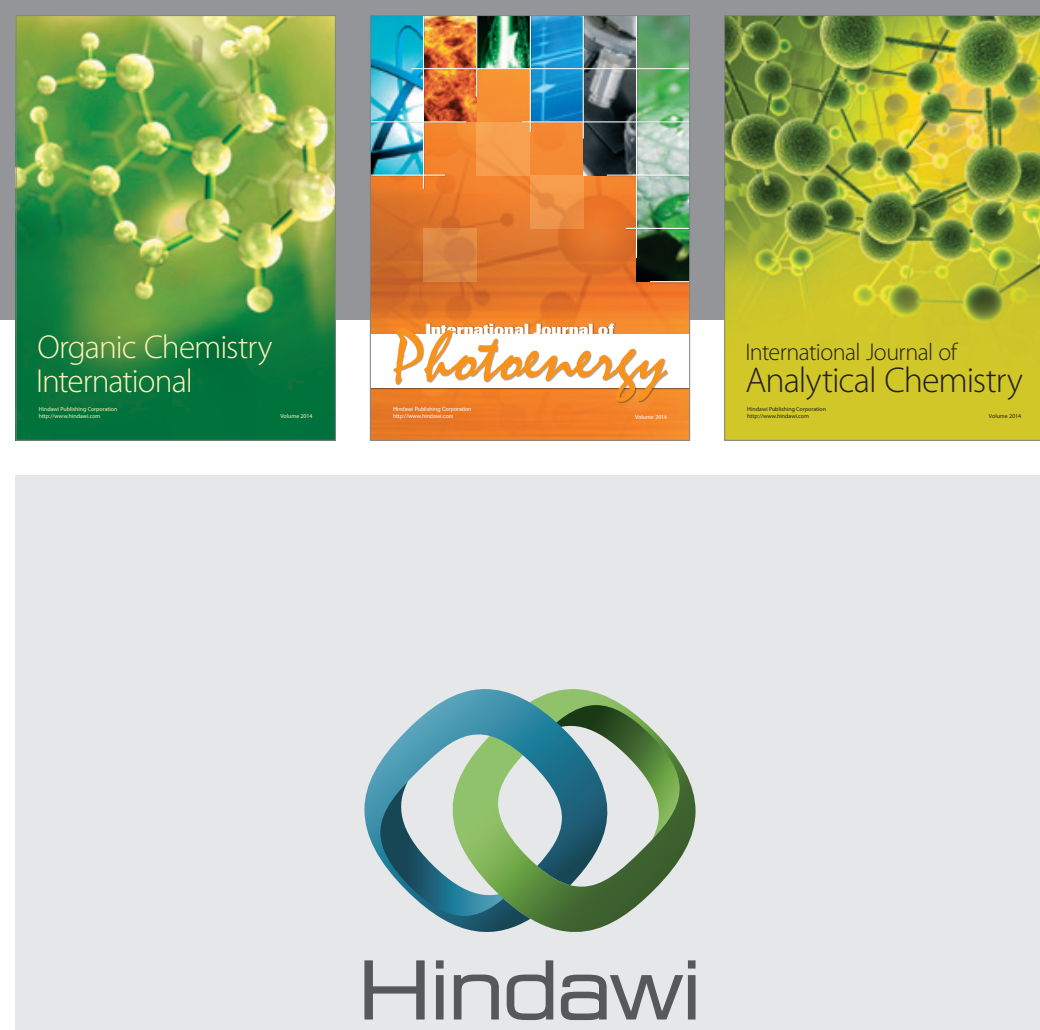

Submit your manuscripts at

http://www.hindawi.com
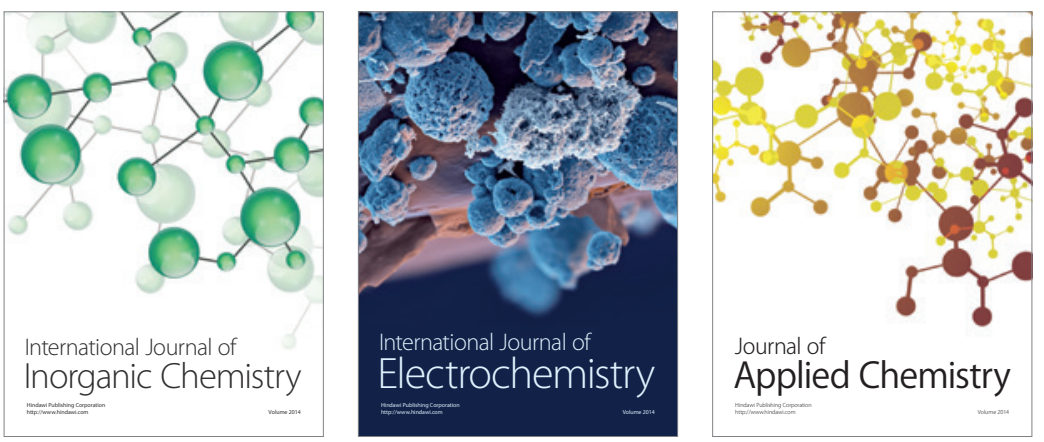

Journal of

Applied Chemistry
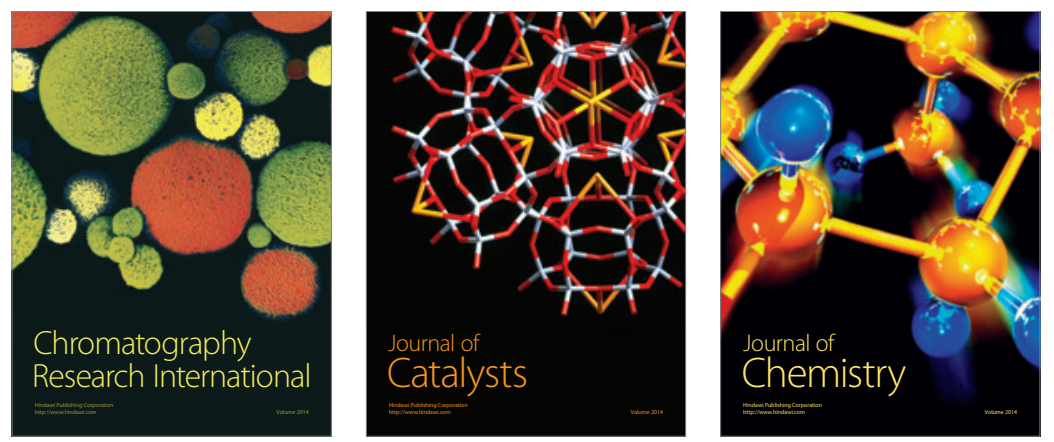
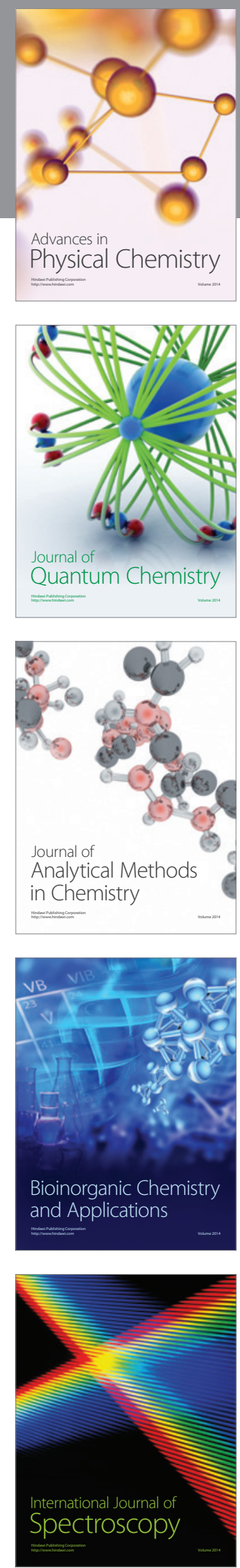